\title{
DEVELOPMENT OF HIGHER EDUCATION CURRICULUM IN MALAYSIA EDUCATION SYSTEM
}

\section{Andria Pragholapati}

Postgraduate School, Curriculum Development, Indonesian University of Education

\begin{abstract}
The curriculum is one component that has a satisfying role in a good education system nationally. The education curriculum is a separate plan and regulates the objectives, content, and teaching materials as well as the methods used to guide the implementation of learning activities to achieve higher education goals. Different education systems in each country are important ingredients in the key to the success of education in a country. One country that competes with Indonesia is the Malaysian Education system.
\end{abstract}

\section{INTRODUCTION}

The curriculum is one component that has a satisfying role in a good education system nationally. The education curriculum is a separate plan and regulates the objectives, content, and teaching materials as well as the ways used as guidelines for organizing learning activities to achieve higher education goals (DIKTI Law No.12, 2012). Based on the educational resolution, realize that education is a conscious conscious effort. Educational planning will be contained in the curriculum pathway or educational pathway for achieving educational goals.

The curriculum has two meanings. The first subject that students must count. Second a special learning program. In the curriculum shown, each level of education. Where each subject has its own curriculum. The curriculum of each subject is related to the competencies that must be agreed on in each subject until the learning portions are assisted by arrangements in the field.

The curriculum contained in the education system in each country has a style in accordance with the national education goals in the country. Associated with considering the education system or curriculum of other countries against the domestic curriculum can also be obtained from comparative studies of education or educational participation. Educational comparative studies or comparative education is the activity of comparing two different education systems between regions as well as between countries, comparing education emphasizes more on the practical side, namely the activity of comparing two different education systems.

Different education systems in each country are important ingredients in the key to the success of education in a country. One country that competes with Indonesia is Malaysia.

\section{KAJIAN TEORI}

Sistem Pendidikan Malaysia 


\section{Profil Negara Malaysia}

Malaysia adalah sebuah negara monarki konstitusional federal yang terletak di Asia Tenggara. Kepala Negara Malaysia adalah Yang di-Pertuan Agong yang digilirkan setiap lima tahun diantara sembilan Sultan Negeri Melayu. Kesembilan Sultan Negeri Melayu yang dapat dipilih menjadi Yang di-Pertuan Agong maupun memilih Yang di-Pertuan Agong adalah Sultan Johor, Sultan Kedah, Sultan Kelantan, Yang Dipertuan Besar Negeri Sembilan, Sultan Pahang, Sultan Perak, Raja Perlis, Sultan Selangor dan Sultan Terengganu. Sedangkan kepala pemerintahan Malaysia adalah seorang Perdana Menteri yang dipilih melalui Pemilihan Umum yang diselenggarakan setiap 5 tahun sekali. Secara Administratif, Malaysia yang merupakan negara berbentuk federasi ini terbagi atas 13 Negara Bagian dan 3 Wilayah Persekutuan.

Malaysia yang memiliki luas wilayah sebesar $329.847 \mathrm{~km} 2$ ini terpisah menjadi dua kawasan oleh Laut Tiongkok Selatan yaitu Malaysia Barat yang berada di semenanjung Malaysia benua Asia dan Malaysia Timur yang berada di Pulau Kalimantan. Di Malaysia Barat, Malaysia berbatasan darat dengan Thailand di sebelah utaranya, sedangkan di sebelah barat adalah selat Malaka dan sebelah timur adalah laut Tiongkok Selatan. Di Selatan Malaysia Barat adalah Singapura yang dipisahkan oleh selat Johor. Di Malaysia Timur, Malaysia berbatasan dengan Brunei Darussalam di sebelah Utaranya sedangkan di sebelah Selatan adalah Indonesia. Sebelah Timur Malaysia Timur adalah Laut Sulu dan Laut Sulawesi, sebelah utaranya adalah laut Tiongkok Selatan. Ibukota Malaysia adalah Kuala Lumpur sedangkan Putrajaya merupakan pusat pemerintahan persekutuan.

Jumlah penduduk Malaysia sebanyak 31.381.992 jiwa (estimasi Juli 2017) yang mayoritas penduduknya adalah beragama Islam (61,3\%). Bahasa Malaysia yang pada dasarnya berasal dari Bahasa Melayu adalah bahasa resmi negara Malaysia. Bumiputera (gabungan suku Melayu, Orang Asli, Dayak dan Anak Negeri) merupakan suku terbesar di Malaysia yaitu sebanyak $61,7 \%$ sedangkan suku lainnya seperti Tionghoa sebanyak 20,8\%, suku asli Sabah/Sarawak (Indigenous) sebanyak 11,8\% dan suku India sebanyak 6,2\%. Angka pertumbuhan penduduk Malaysia adalah sekitar 1,4\%. Hubungan luar negeri, Malaysia merupakan salah satu negera pendiri ASEAN. Malaysia juga merupakan negara anggota APEC, PBB, OKI dan lembagalembaga dibawah PBB lainnya.

Di bidang Perekonomian, Malaysia merupakan negara penghasil Karet dan Minyak Sawit Terbesar di dunia. Pendapatan Domestik Bruto Malaysia berdasarkan Paritas Daya Beli adalah sebesar US\$ 926,1 miliar. Sedangkan Pendapatan Perkapita Malaysia adalah sebesar US\$ 28.900,-. Komoditas Agrikultur utama yang dihasilkan oleh Malaysia diantaranya adalah Minyak Sawit, Karet, Kakao, Beras dan Kayu. Di Perindustrian, beberapa Industri penting Malaysia diantaranya seperti pengolah minyak sawit dan karet, perminyakan dan gas bumi, farmasi dan produk-produk elektronika.

Pendidikan di Malaysia

Malaysia mempunyai tingkat literasi penduduk dewasa yang mencapai 94\%, dan memiliki skor 0,671 di Indeks Pendidikan UNDP. Malaysia menempati posisi 62 dalam daftar pendidikan terbaik di dunia dan ketiga di ASEAN. 


\section{Pendidikan Pasca-Pendidikan Menengah}

Setelah menyelesaikan pendidikan menengah, siswa dapat memilih untuk mengejar 1 sampai 2 tahun pendidikan pasca-pendidikan menengah untuk mendapatkan Form VI dan pendidikan matrikulasi untuk persiapan masuk universitas. Pendidikan matrikulasi dipersiapkan untuk memenuhi persyaratanmasuk khusus dari universitas tertentu. Adapun Form VI ditujukan untuk memenuhi persyaratan dari semua universitas.

\section{Pendidikan Tinggi}

Siswa yang telah menyelesaikan pendidikan menengah, mempersiapkandiri untuk menghadapi Ujian Sertifikasi Sekolah Tinggi Malaysia (semacam SPMB) yang diselenggarakan oleh Dewan Ujian Malaysia, dan ujian Matrikulasi yang dilakukan oleh beberapa universitas lokal. Lembaga pendidikan tinggi mencakup universitas, akademi, dan politeknik. Program yang ditawarkan beragam mulai sertifikat, diploma, dandegree levels. Pada tingkat sarjana pendidikan ditempuh selama 3-4 tahun.

\section{REFERENCES}

Ade, M.S., Tjutju, Pragholapati, A., 2016. GAMBARAN KUALITAS HIDUP PADA LANSIA DI BALAI PERLINDUNGAN SOSIAL TRESNA WERDHA CIPARAY BANDUNG TAHUN 2016.

http://ejurnal.stikesbhaktikencana.ac.id/file.php?file=preview_mahasiswa\&id=532\&cd=0b2173f f6ad6a6fb09c95f6d50001df6\&name=JURNAL\%20SAKINAH\%202016.pdf.

Andria Pragholapati, M.L., 2017. HUBUNGAN MASALAH KESEHATAN JIWA DENGAN STRATEGI KOPING SESEORANG YANG MENGALAMI PERCERAIAN DI KOTA BANDUNG, in: Seminar Nasional Dan Workshop Keperawatan " Penguatan Profesi Keperawatan Dalam Peningkatan Pelayanan Keperawatan" Continuum of Care Dari Ketergantungan Menuju Kemandirian Hidup Yang Berkualitas. ISBN: 978-602-14422-8-9.

Andria Pragholapati, R., 2018. DEVELOPMENT OF THE INDONESIAN NATIONAL QUALIFICATIONS FRAMEWORK FOR NURSING CURRICULUM, in: International Conference on Education and Regional Development 3rd (ICERD) 2018 "Curriculum for Generation of Discruptive and 4th Industry Revolution Era.” p. 44.

Andria Pragholapati, R.M., 2017. HUBUNGAN BULLYING DENGAN KEMAMPUAN SOSIAL PADA REMAJA DI SMK MVP KOTA BANDUNG TAHUN 2017, in: Konferensi Nasional Keperawatan Kesehatan Jiwa XIV Di Kalimantan Selatan Tahun 2017.

Andria Pragholapati, T., 2018. HUBUNGAN PENGGUNAAN SMARTPHONE DENGAN KUALITAS TIDUR PADA REMAJA DI SMK X BANDUNG, in: Konferensi Nasional Keperawatan Kesehatan Jiwa XV Di Hotel Four Point By Sheraton Makassar Sulawesi Selatan. pp. 1-7.

Ardiana, F., Nurlianawati, L., Pragholapati, A., 2016. Gambaran Fungsi Kognitif Pada Lanjut Usia (Lansia) Di Panti Jompo Muhammadiyah dan Yayasan Pondok Lansia Tulus kasih. 
Ariani, A., Pragholapati, A., Pratama, A.S., 2020. Information Communication Technology (ICT) In Midwifery Education: A Review of the Literature, in: The 3rd International Seminar on Global Health (ISGH) "Technology Transformation in Health Care for Better Life" Bandung, West Java, Indonesia. http://repository2.stikesayani.ac.id/index.php/isgh3/article/view/352, pp. 66-69.

Ismawati, Y., Pragholapati, A., 2020. KEJADIAN GASTRITIS DI DESA CINUNUK WILAYAH KERJA PUSKESMAS CINUNUK KABUPATEN BANDUNG.

Ismawati, Y., Sumbara, Pragholapati, A., 2018. HUBUNGAN POLA MAKAN DENGAN KEJADIAN GASTRITIS DI DESA CINUNUK WILAYAH KERJA PUSKESMAS CINUNUK KABUPATEN BANDUNG.

Pragholapati, A., 2020. Self-Efficacy Of Nurses During The Pandemic Covid-19.

Pragholapati, A., 2020. COVID-19 IMPACT ON STUDENTS. osf.io.

Pragholapati, A., 2020. RESILIENSI PADA KONDISI WABAH COVID-19.

Pragholapati, A., 2020. STRES KERJA PERAWAT YANG BEKERJA DI UNIT GAWAT DARURAT (UGD) RUMAH SAKIT AL ISLAM (RSAI) BANDUNG.

Pragholapati, A., 2020. MOTIVASI KERJA PERAWAT DI RUANG RAWAT INAP RSUD MAJALAYA KABUPATEN BANDUNG.

Pragholapati, A., 2020. MENTAL HEALTH IN PANDEMIC COVID-19.

Pragholapati, A., 2020. RESILIENSI PERAWAT YANG BEKERJA DI UNIT GAWAT DARURAT (UGD) RUMAH SAKIT AL ISLAM (RSAI) BANDUNG.

Pragholapati, A., 2020. NEW NORMAL “INDONESIA” AFTER COVID-19 PANDEMIC.

Pragholapati, A., 2019. THE EFFECT OF BRAIN GYM TO THE LEVEL OF DEPRESSION IN GERIATRIC AT BALAI PERLINDUNGAN SOSIAL TRESNA WERDHA CIPARAY BANDUNG. J. Sk. Keperawatan 5, 128-146.

Pragholapati, A., Munawaroh, F., 2020. RESILIENSI PADA LANSIA. J. Surya Muda 2, 1-8.

Pragholapati, A., Ulfitri, W., 2019. Gambaran Mekanisme Coping pada Mahasiswa Program Studi Sarjana Keperawatan Tingkat IV yang Sedang Menghadapi Tugas Akhir di Sekolah Tinggi Ilmu Kesehatan X Bandung. Humanit. J. Psikol. 3, 115-126.

Prasetyo M, D., Nurlianawati, L., Pragholapati, A., 2017. GAMBARAN TINGKAT KECEMASAN PADA PASIEN PRE OPERASI FIBROADENOMA MAMMAE DI RUANG GUNTUR RUMAH SAKIT TK II DUSTIRA CIMAHI TAHUN 2017. http://ejurnal.stikesbhaktikencana.ac.id/mahasiswa.php?detail=mahasiswa\&id ....

Rahmawati, S.D., Mulyati, T., Pragholapati, A., 2015. HUBUNGAN BODY IMAGE DENGAN POLA DIET PADA REMAJA PUTRI DI SMAN 24 BANDUNG TAHUN 2015. http://ejurnal.stikesbhaktikencana.ac.id/file.php?file=preview_mahasiswa\&id .... 
Rosmala, I., Jundiah, S., Pragholapati, A., 2017. TINGKAT KECEMASAN PADA KELUARGA PASIEN DI RUANG ICU RSUD MAJALAYA KABUPATEN BANDUNG TAHUN

http://ejurnal.stikesbhaktikencana.ac.id/file.php?file=preview_mahasiswa\&id=517\&cd=0b2173f f6ad6a6fb09c95f6d50001df6\&name=Jurnal\%20Imas\%20Rosmala\%202017.pdf.

Septriani, D., Sari, Y.R., Pragholapati, A., 2019. The Relationship of Social Support With the Anxiety Level of Parents of Children with Thalassemia of Pre-School Age that Works in the Activities of Blood Transfusion in Hospital " $X$ " Bandung, in: The 2nd Bandung International Conference on Collaborative Health Research Research. Prama Grand Preanger Hotel Bandung, West Java, Indonesia 7th - 8th of October 2019. p. 12.

Virgona, A., Pragholapati, A., 2019. Enhancing Critical Thinking Skills in Nursing Higher Education in Preparation for the Industrial Revolution 4.0: Literature Review, in: The 3rd International Seminar on Global Health (ISGH) "Technology Transformation in Health Care for Better Life" Bandung, West Java, Indonesia.

Portal Rasmi Kementerian Pendidikan Malaysia. Diakses dari https://moe.gov.my/index.php/my/kurikulum

Yunardi. (2014). Sistem Pendidikan di Thailand. Diakses dari http://www.atdikbudbangkok.org/Sistem-Pendidikan-di-Thailand.pdf

http://unesdoc.unesco.org/images/0021/002152/215280E.pdf

http://unesdoc.unesco.org/images/0015/001524/152453eo.pdf

https://www.icnvoicetolead.com/wpcontent/uploads/2017/04/ICN_AVoiceToLead_guidancePack-9.pdf

Pragholapati, A. (2020). Depression in Someone Who Has Divorce.

Pragholapati, A. (2020). Anxiety in Someone Who Has Divorce.

Pragholapati, A. (2020). The Role of Nurses in Divorce.

Pragholapati, A. (2020). Marriage and Divorce.

Pragholapati, A. (2020). Mental Health Issues Someone Who Has Divorce.

Pragholapati, A. (2020). Coping Strategies for Someone Divorced.

Pragholapati, A., \& Indonesia, P. RESILIENSI PADA KONDISI WABAH COVID-19. 
Pragholapati, A. (2020). RESILIENSI PERAWAT YANG BEKERJA DI UNIT GAWAT DARURAT (UGD) RUMAH SAKIT AL ISLAM (RSAI) BANDUNG.

Pragholapati, A. (2020). NEW NORMAL “INDONESIA” AFTER COVID-19 PANDEMIC.

Pragholapati, A. (2020). STRES KERJA PERAWAT YANG BEKERJA DI UNIT GAWAT DARURAT (UGD) RUMAH SAKIT AL ISLAM (RSAI) BANDUNG.

Pragholapati, A. (2020). MOTIVASI KERJA PERAWAT DI RUANG RAWAT INAP RSUD MAJALAYA KABUPATEN BANDUNG.

Pragholapati, A. (2020). MENTAL HEALTH IN PANDEMIC COVID-19. Available at SSRN 3596311. 